\title{
Enhanced Logistics Information Service Systems Performance: Using Theoretical Model and Cybernetics’ Principles
}

\author{
SALEH ALI ALOMARI ${ }^{1 *}$, SAFWAN AL SALAIMEH ${ }^{2}$, \\ EMRAN AL JARRAH ${ }^{1}$, MOWAFAQ SALEM ALZBOON ${ }^{1}$
}

1Faculty of Science and Information Technology, Jadara University, Irbid, JORDAN

2 Department of Software Engineering, Faculty Information Technology, Aqaba University of Technology, Aqaba, JORDAN

\begin{abstract}
Outsourcing logistics has established itself in the area of the LSP (Logistics Service Provider), which offers a range of services to its customers. In this line, transportation is characterized as one of the most important services, and therefore efficient fleet management is essential for establishing a high level of customer service. In this paper, we considered intellectual procedures for modeling the management of logistics information service system in the class of the problem, solved method of the theory of queuing system (QS). Examples of constructing mathematical models for the management of logistics information systems are given.
\end{abstract}

Key-Words: - Logistic, Queuing theory, Mathematical model, Management system, Construction.

Received: October 11, 2019. Revised: March 26, 2020. Accepted: April 8, 2020. Published: April 27, 2020.

\section{Introduction}

Logistics as a form of knowledge know since ancient times, inutility its competence included the art of rational measurement, smart calculation and logical reasoning. The idea of logistics is based on the integration of planning, control and management of production and economic support, and information cybernetic maintenance of a set of interrelated divisions of a complex management system for purpose of coordinating material, financial and information flows. Methodology basic logistics are method of system analysis, modeling, operation research, identification, aggregation, coordination, optimization and decision-making[1].

Logistic is defined as the science of integrated organization and technological management of the goal is to minimize the overall costs from the inconsistency of the operation of subsection between units produced to misbalance in the system due to and the desire to achieve the individual goals of individual subsystems. At present, the production and industrial, construction and transport, commercial and selling logistics, at the completion stage there as information and computer logistics.

Logistics system of any type and the assignment contains functional subsystems and tools.
To the functional link in the production logistics supply, storage of raw materials, manufacturing of the finished products, sending goods to the warehouse or intermediate consumer, the final selling, and consumption of finished products. Instrument means of logistics systems is hardware (computer), informational, organizational, mathematical, algorithmically, program support. These tools often refer to information and computer support for decision-making and this system with such tool is called information computer logistics system specific type. From this point of view, the term information computer logistic system basically concedes with the concepts of integrated information management systems specifically type. Computerized logistics information service system: it is a kind of administrator coordinator for the organization of a rational work of a set of interrelated information management systems.[2-4]

\section{Preliminary Knowledge}

The logistic system construction processes should fit the coordination of material or products, employees and information so that the requested materials are available on a proper price, at the right place, on time, with considering both of quality and quantity, for the Right customer (7 R's)[5]. 


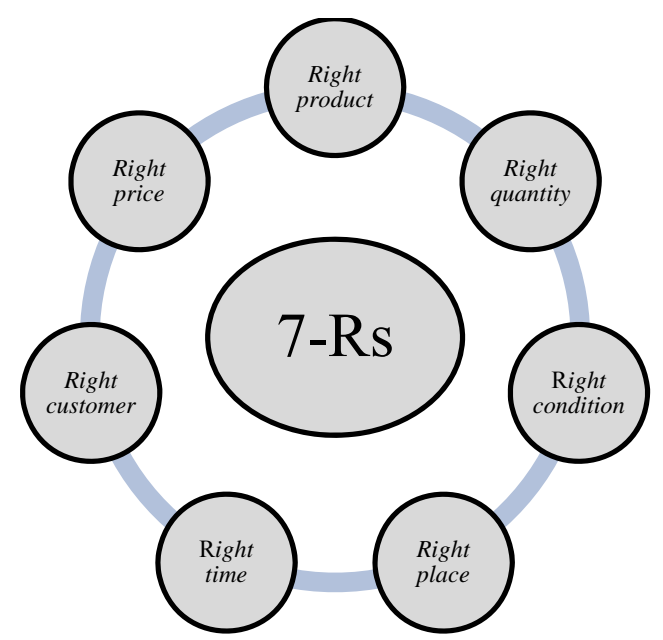

Figure 2.1: The '7-Rs' model.

The basic logistics approach with '7-Rs', see Figure 2.1: right product, right quantity, right condition, right place, right time, right customer, and right price[6].

\subsection{The basic business management:}

In general, there are two different types of management: managing things and managing people, management of things refers to the management of material elements of production: technological processing, machines, equipment, aggregates, mechanisms, and so on. This kind of management is studied by technical sciences. Production management studies the second type of management of people, labor, groups and carrying out process of production of material goods. Management of local production involves the implementation of control actions of government on the labor collectives of factories and workshops, sites, brigades and through them tangible elements of production, to achieve the greatest results at low cost [13].

Any company includes its own production with its service and production management system. In production, as is known, the process is tangible and ends with the manufacture of certain products.

In the management system, the processes are informational and ends with formation of management decisions, on the basis that generates control actions. The latter are various events, aimed at achieving management goals.

Enterprise management (association) is the preparation and implementation of decisions in all areas of the enterprise, aimed at achieving the main goal. The main goal of the enterprise's activity is derived from the social goal of local production. Also consists of achieving plans, tasks and contracts for the production and the supply of high quality products to meet the needs of the population, national economy and export in the respective types of products at the minimum total cost of their research and designing, manufacturing, appeal and operation (consumption).

To achieve the main goal of the enterprise, it is necessary to achieve a number of basic task characteristic of certain areas of the enterprise. These tasks are as follow:

- Rhythmic fulfilment of plans, assignments, contracts;

- Ensuring continuous compliance of technical level, product quality with the needs of the population, national economy and export;

- Increasing the intensity and balance of the use of all types of resources (labor, material, financial, basic production assets) raising and maintaining their quality level, reduction of their unit's costs per unit of production;

- Improving the production and technical base of the enterprise in accordance with the latest achievements of science, technology, organization of production;

- Increasing job satisfaction, satisfaction of material, income needs of team members, improvement of working conditions, sales and rest, increase the social activity of each worker;

- The implementation of enterprise standards and requirements for the impact of the production process and manufactured products on the environment, rational use of natural resources, their recovery and reproduction;

- Increasing the level of production organization and enterprise management.

The management structure of the modern enterprise is built as linear -functional or (linear headquarter) in which the subordinate linear managers of the relevant production units have necessary staff of functional units and performers. The composition and number of functional units for different levels of management is different. Characteristics trends in the development of management structures is the increasing role of functional services for the provision of production repairs, adjustment, transport, tool, as so on.

Centralizing data servicing enterprise wide functions and the linear executives, including foremen, completely from responsibility for these functions. At the same time linearly - staff management is taken at the higher level, namely at the level of production and building.

\subsection{Entity computerized enterprise management system:}

Computerized enterprise management system - it is a man machine system, providing computerized 
data collection and processing, necessary to optimize enterprise management as autonomously, as in the composition of the computerized control system of higher levels of the hierarchy (association, sub sectors and industries).

Man - machine character computerized systems of enterprise management due to the fact that the system should create and maintain a business and creatives environment, to motivate workers to achieve the best performance, provide conditions for continuous improvement of general educational and professional and cultural level working.

Human factor management cannot be fully transfer by computers. Therefore, in computerized control systems, the leading role in generating and decisionmaking remains with the leaders. Software mathematical methods and computing are only tools for processing productive information and preparation of components of management decision.

An enterprise as a management object is a complex, large system component of many interacting subsystems and elements of the different nature of technical, technological, organizational and economical.

The primary goal of computerized enterprise management system is to effectively and proper execution of the main functions of the management in the enterprise through the use of mathematical methods, software and hardware for information processing of advanced techniques for organizing all operations of the information cycle using computers and peripheral devices. To achieve this goal must be respected the following principles of cybernetics[7]:

- Optimality principle: it is consisting in the choosing the best option for influencing a controlled object by comparing the options base on a quality indicator or an optimality criterion.

-Distinguish general criteria of optimality for the entire control system and local for its separated subsystems. However, local criteria must meet the general criterion of the entire system, otherwise, the operation of the latter will encounter a contradiction in the interests of individual subsystems.

-The development of an optimal solution is carried out with the help of economic and mathematical methods and computer technology.

- Black box principles - A black box is a system in which only input and output values are available for observation, internal communications unknown. The behavior of the systems is judged by the reaction of the output values to the change in input. This principle underlines the construction of simplifies mathematical models connecting input and output quantities. This principle is especially important for the study of complex economic systems whose internal process cannot be formalized.

- Principle of external addition: involves the consideration and system not an isolation, but taking into account the relationship with the external environment. For example, enterprise management system is analyzed from two sides: as a relatively isolated complex system and as an element of the industry management systems.

- Modeling principles - i.e. mapping using the model of information process occurring in complex dynamic systems in the form of mathematical models, graphs, network graphs, and so on. Modeling is implemented using procedures in the computer.

- Feedback principle - i.e. the connection between the output control system and its input carried out through a controlled system. Feedback information is a condition for the functioning of the system, its opposition to external influences and indignation an example of feedback is the information received at the enterprise about the demand for its products or about the behavior of manufactured machines in operation, and so on.

- Feedback if computerized control system is the flow of information about the production process that is the flow of credentials from the controlled system to the control.

- The principles of the necessary and sufficient diversity of the system: according to which the complexity of the control systems must be no less than complexity of the managed object. This principle is implemented in the construction of an organization management structure in accordance with the composition and complexity of the management function.

All types of computerized control systems accepted from national economy can be classified according to such characteristics as the nature of the control object, the level of hierarchy and the degree of computerized control actions. To understand the essence of computerized enterprise management systems, it is necessary to consider its features and position in relation to other types of computerized management systems.

Demanding on the nature of the control object. The following type of computerized control systems are distinguished:

1. Computerized process control systems. This category includes computerized control systems that control the operation of computerized lines for various purpose, as well as various large technological units. 
2. Computerized control systems for specific work package. These include computer - aided design systems, computerized research systems, computerized scientific and technical information systems.

3. Large organizational and economic computerized control systems and production systems manager. So, the essence of the computerized control system is that it is, firstly, machine and secondly, organizational and economics, thirdly, mainly information, the corresponding system covering the management process by all parties of the enterprises production and economic activities [8].

\section{Model Formulation and Theoretical}

\section{part.}

\subsection{Performance criteria for enterprise management:}

The purpose of any management system is the need of society, the degree of compliance of the system with the goals called its effectiveness. The efficiency of the system $E$ depends on its own characteristics (states) Z, environment parameters (input effects) $\mathrm{X}$ and goals $\mathrm{A}_{\mathrm{s}}$

$$
E=q\left(Z, X, A_{s}\right),
$$

The $\mathrm{q}$ functionality is called the performance criterion. Depending on whether you can find a functional q, specifying the numerical value of efficiency, distinguish between qualitative and quantities goals.

Quality goal is not to specify a certain substantive condition so, the goals (will ensure the operation of the system) and (execute the plan) are quality. The corresponding criteria can take only two values: 1if the condition is met; $0-$ if the condition is not met.

A quantifiable goal is set a the desire to increase the value of efficiency, that is, the goal As can be expressed by the following functionality

$$
A_{s}=\max _{x \in X} q(Z, X) .
$$

Quantifiable goals allow to optimize the process of functioning or building a system and makes recommendations for optimal management. In that sense quantitative goals, certainly more preferred and constructive. Qualitative goals generally do not have a degree of certainly sufficient to build a mathematical model. Therefore, as knowledge expands, in the stated goals should be replaced by quantifiable, which corresponds to the construction of the efficiency criterion.
The type of $q$ criterion depends on the specifies of a particular system and, depending on this, can be very different. Experience in building performance criteria allows you to formulate some general principles that, although it does not guarantee success, help to avoid blunders, often quarters heavy consequences:

1. Compliance principle: the essence of this principle is to maximize the efficiency criterion, which corresponds to the optimization of the system.

2. Manageability principle: performance criterion should be function of management actions, that is, the vector of input effects $\mathrm{X}=(\mathrm{X}, \mathrm{g})$ must contain a vector of management actions $\mathrm{g}=(\mathrm{g} 1$, ..., gm), which allows for system optimization.

Efficiency is usually determined for fixed goals $A_{s}$ and system states $Z$, then, in accordance with the principle of manageability, the performance criteria will be:

$$
\mathrm{E}=\mathrm{q}(\mathrm{X}, \mathrm{g})
$$

Depending on the knowledge of the person making the decision on the properties of management input effects $\mathrm{X}=\left(\mathrm{X}_{1}, \ldots, \mathrm{X}_{\mathrm{n}}\right)$ the system optimization process for this criterion will be all follows:

3. Deterministic, if vector $X$ is known and fixed, that is, included in performance criteria as a set of parameters;

4. Probabilistic, if vector $X$ changes the values of its components in accordance with a given probabilistic distribution;

5. Game, if only the region of permissible values of the vector $\mathrm{X}$ is known.

In each of the cases considered their mathematical model is used to optimize the system: function for finding extremums of functions, theory of statistical solutions, game theory.

6. Incoming form principle. Performance criterion must be consistent with the functions of its variables and whenever possible with the minimum number of local extremes. Implementation of this principle is also mandatory, like the first two, but it greatly facilitates the optimization of the system according to the selected performance criterion.

The problem of management at the enterprise can be formulated as follow: allocate resources at each time point of the planning period so that the goal is achieved the fulfilment of plan target, but management criteria sought to extremum. This leads to construction of a company management system based on a global criterion. 
$\phi=\operatorname{extr} \phi[x(t), u(t), \sigma(t)$

Resource constraints $\zeta \leq \zeta_{o}$ ) here $\mathrm{x}(\mathrm{t}), \mathrm{u}(\mathrm{t}), \sigma(\mathrm{t})$ respectively, the state vectors of the managed object, control and disturbing influences on the management object (enterprise). Criteria for managing the object of national economy, particular commercial enterprise, should serve under restrictions on the obligatory nomenclature of products. If the goal of the enterprise is to obtain maximum profit, then the corresponding efficiency criterion is written in the form:

$$
P=\sum_{i} C_{i} V_{i}-\sum_{j} C_{j} W_{j},
$$

Where $C_{i}, V_{i}$ - price and the number of products of i-th type; $\mathrm{C}_{\mathrm{j}}, \mathrm{W}_{\mathrm{j}}$ - cost and amount of used resource $\mathrm{j}$-th type. So that, profit can be criterion of enterprise management, it is necessary to have a directly proportional relationship between profit and economic incentive funds of this enterprise, i.e.

$$
\phi=\varphi P,
$$

Where $\phi-$ economic incentive funds including national incentive funds $\phi_{1}$, social construction $\phi_{2}$, and production development $\phi_{3} ; \mathrm{P}-$ enterprise profit; $\varphi$ - planned regulations.

Only in this case, while maximizing the funds of the enterprise, it automatically maximizes profit, that is

$$
P \rightarrow \max \text { at } \varnothing \rightarrow \max \quad \phi=\varphi P,
$$

In this way, as a creation for managing an commercial enterprise, one should choose linear combination of economic incentive funds

$$
\varphi_{1} \emptyset_{1}+\varphi_{2} \emptyset_{2}+\varphi_{3} \emptyset_{3} \rightarrow \max
$$

However, any enterprise works in conditions of partial uncertainty. Probability theory and mathematical statics make it possible to construct a management taking into account the arising random failures according to the probability criterion.

For an enterprise as a system with stochastic properties as a criterion, you can used by maximum of the probability of fulfilling nomenclature plans for the most important types of products with regard to quality and sales in general, with restrictions for production resources, approved by higher organizations. Such a criterion, given the critical environment in which the company is fixed, gives an optimal allocation of production resources for the implementation of given program and does not contradict the solution of a complex of optional tasks for nomenclature plans according to the profit criterion.

In terms of maximizing, the likelihood of executing nomenclature production plans is a task of stochastic programming. It is known that when a deterministic solution of stochastic programming problems is found.

Let the task of limiting the general form

$g=(N, \sigma) \geq 0$,

Where $\mathrm{N}$ - plan vector; $\sigma$ - vector of undefined parameters.

If $\widehat{N}$ - any plan, in that case is not guaranteed that there is no implementation of random parameters $\sigma$ such that the condition $g=(N, \sigma) \geq 0$ not performed.

Impossibility, sometimes inexpediency of the requirement that the chosen plan satisfy the constrains in any realizations of random parameters, leads to less stringent conditions, namely instead of a hard limit, $=(N, \sigma) \geq 0$, there is a requirement to guarantee the fulfillment restrictions with a probability not lower than the given

$$
P(g(N, \sigma \geq o) \geq 1-\gamma,
$$

Such a probabilistic concept of guaranteeing the feasibility of a plan contains the idea of introducing risk in planning, moreover, the parameter $\gamma$ numerically expresses the value of risk. It is natural that in practical calculations an unacceptably large value of $\gamma$, and it is traditionally accepted within $0.05-$ 0.1 .

Similar modifications have to be done and applied to the objective function of the optimal planning problem. If $f(N, \sigma)$ - is a function expressing the effectiveness of a plan for a given $N, \sigma$, the task of finding a deterministic plan for random parameters $\sigma$ is naturally to be formulated:

$$
\begin{aligned}
& \max \frac{h}{P\{f(N, \sigma)>h\}} \geq 1-\gamma \\
& P\{g(N, \sigma) \geq 0\} 1-\gamma .
\end{aligned}
$$

These expressions are a mathematical programming problem, different from the original task only by the type of the objective function and constraints, and no longer include the actual values of the parameters $\sigma$, which are unknown when planning and their probabilistic characteristics are the parameters of the distribution laws. This task can be interpreted, for example: it is required to arise to the limit the limit $\mathrm{h}$ below which the efficiency can decrease only with a small 
probability $\gamma$. Thus, the risk profile extends to the effectiveness assessment. In system $h$ it acts as a level of profit or sales [14, 19-21] .

Consider the allocation of enterprise resources when using the maximum probability criterion for the implementation of nomenclature plans with appropriate restrictions, i.e.

$$
\max P(r)
$$

Where r- event of inequality, $N_{i j} \geq N_{i j_{0}} ; N_{i j}$ - the actual release of the product $\mathrm{i}$ in the planned time interval

$$
\left[T_{j}, T_{j+1}\right] ;=1,2, \ldots, k
$$

$N_{i j_{0}}-$ the planned release of the product $\mathrm{i}$ in the same interval. While $\mathrm{k}$ is determined from the condition

$$
\sum_{i=1}^{k}\left|\left[T_{i}, T_{i+1}\right]\right| \max _{i} U_{i}+\left(T_{k}-T_{k-1}+\Delta\right) ;
$$

Where $\left[T_{i}, T_{i+1}\right]$ - the length of the planned time interval; $U_{i^{-}}$production cycle of $\mathrm{i}$-th product; $\Delta-$ time reference.

Thus, the management task for any production unit can be formulated as follows: "find a resource allocation vector $\varphi$, that maximizes the specified criterion $P(r)$ and satisfied the relevant cost $\operatorname{limits} \zeta \leq \zeta_{0}$ ”[8].

\subsection{Place of logistic management in the company}

Clarify the concept of logistics management and determine its place in the overall management structure of the company clarify the concept of logistics management and determine its place in the overall management structure of the company [15].

According to the management theory in a market economy. The concept of management is interpreted in two ways: first one - as a combination of tools and forms of production and sales management to achieve strategic and tactical and operational objectives and company tasks; second one - as a tool for managing relationships within the company's personnel with external partners on business and consumer products (services).

In the first sense, the logistics management in the firm is a synergy of the main management functions (organization, planning, regulation, coordination, control, accounting and analysis) elementary and complex logistics activities to achieve the goals of the micro - logistics system.

In the second sense, the logistics management these are management personnel role, according to their role in the management hierarchy of the firm and organizational levels of the logistics system can be divided into:

1. Top management;

2. Middle management;

3. Lower management.

When building modern micro logistics systems, it is very important to determine the place of logistics management in the overall management structure of the company and identifying areas of interaction with other areas of management.

The modern management system of the company is a composition of the organization structure of management with functionally oriented areas of activity (finance, investment, production, marketing and sales, innovations, personal and etc. ), combined strategic and tactical and other objectives.

From the point of view logistics, the implementation of the function of strategic (tactical and operation) and functional management should contribute promotion logistics mission of the company, coordination strategies.

Features of logistics management is that it is both at strategic and at tactical (operational) goals and tasks associated with all functional areas of management in material procurement management processes, production and sales finished products. It is often very difficult to separate the scope of logistics and other types of management, therefore, they usually single out the main coordinating and integrating functions of logistics management at the highest levels of the management hierarchy in a company.

\subsection{The role and importance of logistics in the enterprise}

Currently, in order to succeed in business, it is not enough to use marketing approaches, it requires the use of modern highly efficient methods and methods for managing flow processes, such as logistics. Logistics as a practical activity has steadily found its niche in the management of modern enterprises. Logistics is of great importance for customers, suppliers of the enterprise, its owners and shareholders. Logistics coordinates all structures of the enterprise (direction, ordering and distribution of products from the manufacturer to the final consumer, taking into account profitability, performance, and productivity).

The main task of production logistics is to create and ensure the effective functioning of an integrated material management system in an enterprise. The role of logistics in a modern company is optimization and integral. Optimization of all 
processes in the enterprise provides logistics. Solving the issue of optimizing all processes in an enterprise is impossible without applying principles, methods, and logistics functions.

The use of logistics concepts and systems allows firms to reduce all types of stocks of products in production, supply and marketing, accelerate the turnover of working capital, reduce production costs, and ensure complete satisfaction of consumers in the quality of goods and services. The potential of logistics allows increasing the organizational and economic sustainability of the enterprise in the market. The obligatory component of the organizational structure of a successful enterprise is the logistics department. The enterprise's logistics service includes the following functions: operational planning of finished products; operational management of technological processes of production; planning the supply of material resources; product quality control; maintenance of product and service quality standards [16].

As part of the logistics system in the enterprise, five levels of management are implemented: The administrative level; position control level; the level of implementation of individual orders according to the schedule; operational management of informational material flows; on-line control.

Logistics covers the whole spectrum of the company's activities: planning, implementation, cost control, movement and storage of the company's materials. At the stages of production development, logistics reduces costs and manufactures products on time. The company's logistics activities include customer service, transportation, inventory management, information flow management.

Transport is the most important factor of logistics; no company can operate without the delivery of finished products to customers. Inventory management logistic activities provide high enterprise flexibility and time for reorganization or production system according to circumstances. Modern experts in the field of logistics note the significant role of stocks in the modern organization of product distribution and include inventory management as factors that allow improving the quality of logistics services for participants in commercial relationships. Due to a number of factors that influence the efficiency of product distribution, there is a need for inventory to fulfil the following logistic functions: geographical specialization, consolidation of resources, balancing supply and demand; protection against uncertainty[9]. The final logistic operation at the enterprise is order processing.
The interaction of individual links of the logistics chain is carried out at the technical, economic, financial and other levels of integration. The use of logistics accelerates the process of obtaining information and increases the level of service of the production process. Large freight forwarding companies and express delivery companies such as Ryder, DHL, Schenker - BTL, Federal Express, UPS, Lesnay, TNT carry out a large number of logistic operations, integrating logistic functions in the territorial area on the basis of product orientation. This allows firms - manufacturers of finished products and shippers to reduce the costs associated with transportation, cargo handling, and storage and improve the quality of logistics services[10]. Features of the logistics systems are characterized by a wide range of goods sold; independent, dynamic demand for goods; high service requirements; the proximity of the warehouse network to the consumer; the presence of intermediaries.

If the issues of logistics services are not resolved, then it is impossible to carry out effective promotion of goods to the market. For many transport hubs, there is an inconsistency in the interaction of adjacent modes of transport involved in the process of multimodal transportation.

\section{System development}

\subsection{The structure of the information service system:}

Each system for collecting, transmitted information intrinsic organization, which is characterized by the number of servicing devices, opportunities and discipline education queue, the numerical requirements of this incoming stream, discipline queuing. Information system sells with single - line and multi - line, with expectation and with refusal when the instruments are occupied with limited queue by the number of requirements, by waiting time in the service and so on.

Rule according to which the requirement are selected for maintenance, design a service discipline. The most common discipline service is carried out according to the rule: (first came first served). But group service is also possible and service with priorities. In the latter case, absolutely possible, relative and mixed priories service. Under the process of servicing the information flow involves the transfer, admission, and the primary processing of the message. In the queuing theory for temporary service takes time, the maintenance cost of one requirement is given by servicing device. This indicator characterizes the capacity of the servicing device [11, 12, 17-19]. 
The concept of (QS) is one of the main; one includes information about the number and properties of incoming and out coming stream, opportunity to organize queue and discipline of service, ways of moving requirements inside the system, number and interrelated of servicing instruments. Incoming flow and the parameters of the servicing devices are described in statically terms or deterministic time characteristics the time between receipts is a requirement for the system and time maintenance requirements in devices. Discipline of service, introducing logical characteristics, sets the path of the requirements in the system, availability of devices (buffer devices) criteria for selecting the requirements for maintenance (priority) and other ratio.

In this way, information service system as (QS) can be characterized by five parameters:

$$
S_{\text {OCH }}=<I_{\text {inp }}, I_{\text {out }}, T_{\text {ser }}, N_{\text {ser }}, p_{\text {ser }}>\text {, }
$$

Where $\mathrm{I}_{\text {inp }}$-incoming flow of requirements; $\mathrm{I}_{\text {out }}$-out coming flow of service; $\mathrm{T}_{\mathrm{ser}}$ - duration of service; $\mathrm{N}_{\text {ser }}$ - number of servicing units; $\mathrm{p}_{\text {ser }}$ - discipline (strategy) of service.

\subsection{Evaluation of the effectiveness of the information service system:}

The task of modelling logistics information service system at when reengineering (redesign with improvements) the service terminal, the device assumes a response to the next question: how long the subscriber? What the servicing device to the specific moment turns out to be employment? How often does the queue exceed the specified length?

To assess the functioning quality of the existing information service system, the following indicators are used:

$\bar{n}-$ the average number of message per second; arriving for service (intensity of incoming requests flow $\mu$ );

$\overline{t_{s}}$ - the average service time per second (the inverse of the intensity of the service $\left.\overline{t_{s}}=\frac{1}{\mu}\right) ; \overline{n t_{s}}-$ coefficient of equipment use;

$\bar{w}$ - the average number of message waiting to be serviced at a given time; $\bar{g}$ - the average number of messages waiting to be serviced and serviced by system at a given time; $\overline{t w}$ - message waiting time; $\overline{t g}$ - the time spent by the message is unexpected.

The stoical and the significance of these indicators depend on the distribution of applications, arriving for service. The most characteristics are considered hardly boundary cases: uniform and exponential distribution. At uniform time maintenance the following relation holds;

$$
\begin{gathered}
\bar{g}=\overline{n_{0}}=p+\frac{p^{2}}{2(1-p)} ; \\
\overline{t_{g}}=\bar{t}_{s}\left[1+\frac{p}{2(1-p)}\right]=\bar{t}_{s} ;
\end{gathered}
$$

But at the exponential distribution

$$
\begin{aligned}
& \bar{g}=\overline{n_{s}}=p+\frac{p^{2}}{1-p}=\frac{p}{p-1} ; \\
& \overline{t_{g}}=\overline{t_{s}}=\overline{t_{s}}\left[1+\frac{p}{1-p}\right]=\frac{\overline{t_{s}}}{1-p} .
\end{aligned}
$$

Most of the value of the actual service time lies between these two extreme cases: service time, equal constants, they are extremely rare. In real time the maintenance is not great, to consider $\sigma_{i s}=\overline{t_{s}}$, how is this done in the exponential law of the distribution of service time. Therefore, there are several statement queue sizes and the waiting time in them, but such an error is not dangerous. If consider, there are the distribution densities in real terms noisy at $(5-10 \%)$, so in the translated ration makes significant changes.

\section{Simulation results}

The simulation result shows that at $80 \%$ equipment download and queue length when customer service begins catastrophic growth. In this case, a slight increase or decrease in traffic (intensity of the flow of incoming requirements) leads to either significant queue, or to a sharp discipline in system performance. If the equipment utilization factors is $\mathrm{p}=50 \%$, that is an increase in the input traffic to $\mathrm{X} \%$ increase the size of the queue to $\left(\overline{u t_{s}}\right) \mathrm{x} \%$ for the exponential distribution law. If the equipment utilization factors is $90 \%$, that increase in the size of the queue is equal $\left(100 \overline{t_{s}}\right) \mathrm{x}$ $\%$, i.e. in 25 times more.

Slight increase in lead at $90 \%$ the use of equipment leads to 25 multiply the size of the queue in comparison with the case $50 \%$ use of equipment. The same is measured during the stay in the queue. At low equipment utilization rates and the impact of changes, $\sigma_{i s}$ the size of the queue is insignificant. However, for large $\mathrm{P}$ change $\sigma_{i s}$ strongly affects the size of queue. When designing the information flow maintenance system, it is advisable to use the equipment utilization coefficient to take the order $\mathrm{p}$ $=0.5-0.7$. 


\section{Conclusion}

Outsourcing logistics has established itself in the area of the LSP (Logistics Service Provider), which offers a range of services to its customers. In this line, transportation is characterized as one of the most important services, and therefore efficient fleet management is essential for establishing a high level of customer service. In this paper we considered intellectual procedures for modelling the management of logistics information service system in the class of the problem, solved method of the theory of queuing system (QS). Examples of constructing mathematical models for the management of logistics information systems are given.

\section{References:}

[1]. Barreto, L., A. Amaral, and T. Pereira, Industry 4.0 implications in logistics: an overview. Procedia Manufacturing, 2017. 13: p. 1245-1252.

[2].Al Salaimeh, S., Information Technologies of the Distributed Applications Design. Institute Mathematics and Computer Science Journal, India., 2003: p. p.99-103.

[3].Batiha, K. and S. Al Salaimeh, Development sustainable algorithm optimal resource allocation in information logistics systems. International Journal of Computer Applications, 2016. 137(14): p. 8-9.

[4].Al Salaimeh, S., Z. Al Saraireh, and J.H. Al Rawashdeh, Design a model of language identification tool. International Journal of Information \& Computation Technology, 2015. 5(1): p. 11-18.

[5].Lange, S. and D. Schilling. Reasons for an optimized construction logistics. in Proceedings of the 23rd Annual Conference of the International Group for Lean Construction. 2015.

[6]. Wajszczuk, K., The role and importance of logistics in agri-food supply chains: An overview of empirical findings. Logistics and Transport, 2016. 30(2): p. 47--56.

[7].Malindžák, D., T. Olejarz, and A. Gazda, LOGISTICS-SCIENCE OF PRESENTDAY AND FUTURE. Publishing House of Rzeszow University of Technology, 2018: p. 37.

[8].Cokins, G., Performance management: Integrating strategy execution, methodologies, risk, and analytics. Vol. 21. 2009: John Wiley \& Sons.

[9]. Gunasekaran, A. and K.-L. Choy, Industrial logistics systems: theory and applications. 2012, Taylor \& Francis.

[10]. Batiha, K. and S. Al Salaimeh, Elearning. Leonardo Electronic Journal of Practices and Technology, 2007: p. 1-4, Romania.

[11]. Sergeev, V., Logistics in business. Infra, Moscow. , 2010.

[12]. Tian, Y., S.W. Ji, and B. Zhang. Modeling of Logistics Information Service System for Display Industry Based on ARIS. in Advanced Materials Research. 2013. Trans Tech Publ.

[13].Safwan Al Salaimeh, The Optimization Problems of Informational Servicing Logistics Systems by Using Queuing Theory, International Journal of Scientific Research in Computer Science, Engineering and Information Technology, Volume 2, Issue $6,2017$.

[14].Shadi Shawawreh., Saleh Ali Alomari., Mowafaq Salem Alzboon., Safwan Al Salaimeh., Evaluation of Knowledge Quality in the E -Learning System, International Journal of Engineering Research and Technology. ISSN 09743154, Volume 12, Number 4 (2019), pp. 548-553

[15].Safwat Al Tal., Safwan Al Salaimeh., Saleh Ali Alomari., Muhyeeddin Alqaraleh., The Modern Hosting Computing Systems for Small And Medium Businesses, Academy of Entrepreneurship Journal, Volume 25, Issue 4, 2019.

[16].Saleh Ali Alomari ., Putra Sumari., Alireza Taghizadeh, A Comprehensive Study of Wireless Communication Technology for the Future Mobile Devices, European Journal of Scientific Research, Vol.60, No.4, (2011), pp. 583-591, ISSN 1450$216 X$.

[17].Saleh Ali Alomari, Putra Sumari, Sadik A. Al-Taweel, Ahmed M. Manasrah. "CUSTP: Custom Protocol for Audio and Video Conferencing System over P2P Networks". International Journal of Digital Content 
Technology and its Applications, JDCTA, Vol. 4, No. 3, pp. $61 \sim 74,2010$.

[18].Al besoul .K, Salaimeh. S, The Structure of logistics organizational technological system, Journal information society, Vol.4, Num. 7, June, 2007.

[19].Safwan Al Salaimeh, Khaled Batiha, Business Process Simulation with Algebra Event Regular Expression, Information Technology Journal, Volume 5, Number 3, 583-589, 2006, Pakistan

[20].Al Salaimeh., A new model for information logistics system Architecture, Journal of Theoretical and Applied Information Technology, June, Vol.28. No.1, 2011.

[21].Ying Tian, Shou Wen Ji, Bin Zhang, Modeling of Logistics Information Service System for Display Industry Based on ARIS, Advanced Materials Research, Vols. 785-786, pp. 1537-1540, 2013.

[22]. Bani Younes., M, Al Salaimeh, S.,The Optimal Allocation of Simulation Resource in Logistics Information Systems. International Journal of Innovative Science, Engineering \& Technology, Vol. 2 Issue 2, February 2015. 